\title{
Arsenic Accumulation in Panax notoginseng Monoculture and Intercropping with Pteris vittata
}

\author{
L. Y. Lin • X. L. Yan • X. Y. Liao • Y. X. Zhang • X. Ma
}

Received: 12 November 2014 / Accepted: 27 February 2015 / Published online: 27 March 2015

(C) Springer International Publishing Switzerland 2015

\begin{abstract}
Panax notoginseng is a well-known phytomedicine used all over the world. In recent years, a certain As contamination of the herb appeared in its planting area due to elevated soil As concentration. We investigated the feasibility of intercropping with Pteris vittata, an As hyperaccumulator, on the reduction of As accumulation in Panax notoginseng and As transfer and transformation in soil-plant system. Results showed that, intercropping could decrease the As concentrations of Panax notoginseng by $9.1-54.3$ and $30.9-54.3 \%$ and increase the biomasses by 40.7-211.6 and 2.1-153.3\%, respectively, in the H-As (soil As $400.4 \mathrm{mg} / \mathrm{kg}$ ) and M-
\end{abstract}

\footnotetext{
The highlights of this research

$>$ Intercropping with Pteris vittata is a good option for solving As contamination problem of Panax notoginseng in the moderately As-contaminated soil.

$>$ Intercropping could significantly decrease the available As concentration to reduce the probability of As uptake in rhizosphere.

$>$ Intercropping could also promote the As transport to the aboveground part, thereby further reducing the As concentration in root (the main medicinal active part).
}

L. Y. Lin $\cdot$ Y. X. Zhang $(\bowtie) \cdot$ X. Ma

School of Chemical and Environmental Engineering, China University of Mining and Technology (Beijing), Ding No. 11 Xueyuan Road, Haidian District, Beijing 100083, China e-mail: zhangyuxiu@cumtb.edu.cn

L. Y. Lin $\cdot$ X. L. Yan $(\bowtie) \cdot X$. Y. Liao

Beijing Key Laboratory of Environmental Damage

Assessment and Remediation, Institute of Geographic

Sciences and Natural Resources Research, Chinese Academy

of Science (CAS), 11A, Datun Road, Chaoyang District,

Beijing 100101, China

e-mail: yanxl@igsnrr.ac.cn
As (soil As $85.3 \mathrm{mg} / \mathrm{kg}$ ) treatments. Compared to the monoculture, the ratio of the nonspecifically adsorbed As in soil was decreased by 17.8 and $34.3 \%$, and the As transfer factor of Panax notoginseng was increased by 22.2 and $66.3 \%$, respectively, in H-As and M-As treatments. For As speciation, As(III) and As(V) could be detected at the same time only in root and xylem sap of Panax notoginseng in the H-As treatment, and intercropping could increase the ratios of As(III) by 97.8 and $72.4 \%$, respectively. In summary, intercropping with Pteris vittata is an applicable approach to reduce the As accumulation in Panax notoginseng.

Keywords Panax notoginseng $\cdot$ Pteris vittata . Intercropping $\cdot$ Arsenic $\cdot$ Xylem sap

\section{Introduction}

Panax notoginseng (Burk.) F.H. Chen, a rare traditional Chinese medicinal herb, is a well-known phytomedicine used all over the world and has multiple medicinal effects including lowering blood pressure, anti-thrombosis, anti-atherosclerosis, and neural protection $(\mathrm{Ng}$ 2006). The Wenshan Prefecture of Yunnan Province is the main production area of Panax notoginseng, where it has been cultivated there for more than 400 years (Guo et al. 2010). In 2013, the annual local output of Panax notoginseng was about 9 million $\mathrm{kg}$, accounting for more than $85 \%$ of the global output. To date, Panax notoginseng is exported to 14 countries and regions, 
such as Japan, Malaysia, Singapore, the USA, Australia, and so on, and it generates about \$400 million annually in the international trade.

Due to the high background value of As in soil, frequent mining activities, and large-scale use of Ascontaining pesticides in the mid-1990s, Wenshan Prefecture experiences problems of As contamination in soil (Feng et al. 2005; Yan et al. 2011). In recent years, the amount of plantable farmland for Panax notoginseng has dropped sharply, being greatly affected by the expansion of cultivation area and continuous cropping obstacle. A large amount of As-contaminated land was used to cultivate Panax notoginseng, leading to severe problems of excess As content in the plant (Lin et al. 2013). Lin et al. (2013) investigated 31 types of Panax notoginseng preparations in China and found that $56 \%$ of them exceeded the As standard of China Green Trade Standards of Importing and Exporting Medicinal Plants and Preparation (GTSIEMPP 2004, As concentration $<2 \mathrm{mg} / \mathrm{kg}$ ). Therefore, focus on how to control the As concentration in Panax notoginseng is very important.

Pteris vittata L., an As hyperaccumulator, is well known for its unique advantages of high As uptake and large biomass (Chen et al. 2002; Ma et al. 2001). The fern is widely distributed in Yunnan Province, and its As concentration and biomass could respectively reach about $1455 \mathrm{mg} / \mathrm{kg}$ and $4139 \mathrm{~kg} \mathrm{hm}^{2}$ (Xie et al. 2010). It preferentially grows in sheltered and wet places, which is similar with Panax notoginseng. It may be a good choice to reduce the As accumulation in Panax notoginseng by intercropping with Pteris vittata. Intercropping is defined to be the growing of two or more cultivars simultaneously on the same area of land. As a kind of century-old agricultural practice, it is most popular in developing countries and in tropical agriculture. In recent years, some other hyperaccumulators, such as Thlaspi caerulescens, Brassica juncea, and Sedum alfredii, have been intercropped with Oryza sativa L., Triticum aestivum L., and Zea mays L., and the elements were focused on $\mathrm{Cd}, \mathrm{Zn}$, and so on (Gove et al. 2002; Li et al. 2009; Tang et al. 2012). However, research regarding the intercropping with As hyperaccumulator remains very limited.

In this study, a series of experiments were conducted to assess the feasibility of intercropping technology in solving As contamination problem in Panax notoginseng planting areas. Furthermore, the As transfer and transformation in soil-plant system would also be explored. The results would provide important information on the reduction of As accumulation in the medicinal herb Panax notoginseng and even other planting areas of Chinese Herbal Medicine.

\section{Materials and Methods}

\subsection{Pot Experiment}

The pot experiments were conducted in Yanshan County, Wenshan Autonomous Prefecture (Yunnan Province, China). Three kinds of soils with different As concentrations (L-As, M-As, and H-As) were collected from Yunnan Wenshan Arsenic Factory and surrounding areas. The physicochemical properties of soils (Table 1) were determined following SSICA (1980). The soil was air-dried, passed through a 2-mm sieve, and then packed in experimental pots $(10-\mathrm{kg}$ soil per pot). The annual Panax notoginseng was collected from the same field block, and Pteris vittata seedlings were transplanted from nearby hill in Yanshan County. All the plants were cultivated in the planting shed for 30 days and then transplanted to quadruplicate pots for each treatment. There were three cultivation models, such as Panax notoginseng monoculture (eight plants per pot), Pteris vittata monoculture (four plants per pot), and Panax notoginseng-Pteris vittata intercropping (four plants per pot and two plants per pot, respectively). Soil moisture was maintained at $60 \%$ of the field capacity, and the average annual temperature was $16.6^{\circ} \mathrm{C}$. The plants were harvested and rhizosphere soil was collected after 180 days.

\subsection{Xylem Sap Collection}

The xylem sap was collected following Djordjevic et al. (2007). After morning watering, the plants were decapitated $1 \mathrm{~cm}$ above the root, and the root stock was

Table 1 Physicochemical properties of soils for pot experiment

\begin{tabular}{llllll}
\hline & $\begin{array}{l}\text { As } \\
\text { concentration } \\
(\mathrm{mg} / \mathrm{kg})\end{array}$ & $\begin{array}{l}\text { Organic } \\
\text { substance } \\
(\%)\end{array}$ & $\begin{array}{l}\text { Total } \\
\mathrm{N}(\%)\end{array}$ & $\begin{array}{l}\text { Total } \\
\mathrm{P}(\%)\end{array}$ & $\begin{array}{l}\text { CEC } \\
(\mathrm{cmol} / \mathrm{kg})\end{array}$ \\
\hline L-As & 24.8 & 2.4 & 0.1 & 0.1 & 22.1 \\
M-As & 85.3 & 4.2 & 0.2 & 0.1 & 12.7 \\
H-As & 400.4 & 3.9 & 0.1 & 0.1 & 18.3 \\
\hline
\end{tabular}


attached securely to $10-\mathrm{mL}$ syringes by $3-\mathrm{cm}$ pieces of plastic tubing (i.d. $3 \mathrm{~mm}$ ), thus generating an airtight connection. A small vacuum was maintained by pulling back on the syringe and impeding its retraction. For the time course experiment, after decapitation, sap was pooled and collected at 2-h intervals for $24 \mathrm{~h}$. The sap was immediately placed into precooled tubes and then taken back for the laboratory analysis of As speciation and total As concentration.

\subsection{Sample Preparing and Chemical Analysis}

Organic substance was measured following SSICA (1980). Weigh $1.0 \mathrm{~g}$ of soil into an Erlenmeyer flask, pipet $10.0 \mathrm{~mL} \mathrm{~K}_{2} \mathrm{Cr}_{2} \mathrm{O}_{7}$ and $20 \mathrm{~mL} \mathrm{H}_{2} \mathrm{SO}_{4}$ into each flask, add five or six drops of phenanthroline complex, and immediately titrate with the ferrous sulfate solution until the color turns reddish-brown. The analysis of As speciation and total As concentration in the xylem sap, plant, and soil was according to our previous work (Yan et al. 2012). All reagents used for As analysis were guaranteed reagent grade, and the national standard reference materials (plant: GBW-07603; soil: GBW07404) were used for purpose of QA/QC analysis.

\subsection{Sequential Extraction}

The As fractions were extracted from the soil samples using the five-step method reported by Wenzel et al. (2001). One gram of sieved soil $(0.85 \mathrm{~mm})$ was placed into a $50-\mathrm{mL}$ centrifuge tube, and we then extract the nonspecifically adsorbed As fraction (F1), specifically adsorbed As fraction (F2), amorphous and poorly crystalline hydrated $\mathrm{Fe}$ and $\mathrm{Al}$ oxide-bound As fraction (F3), well-crystallized hydrated $\mathrm{Fe}$ and $\mathrm{Al}$ oxide-bound $\mathrm{As}$ fraction (F4), and residual As fraction (F5) by $\left(\mathrm{NH}_{4}\right)_{2} \mathrm{SO}_{4}(0.05 \mathrm{~mol} / \mathrm{L}), \mathrm{NH}_{4} \mathrm{H}_{2} \mathrm{PO}_{4}(0.05 \mathrm{~mol} / \mathrm{L})$, $\left(\mathrm{NH}_{4}\right)_{2} \mathrm{C}_{2} \mathrm{O}_{4}(0.2 \mathrm{~mol} / \mathrm{L}, \mathrm{pH} 3.25),\left(\mathrm{NH}_{4}\right)_{2} \mathrm{C}_{2} \mathrm{O}_{4}(0.2$ $\mathrm{mol} / \mathrm{L}$, ascorbic acid $0.1 \mathrm{~mol} / \mathrm{L}, \mathrm{pH} \mathrm{3.25)}, \mathrm{HNO}_{3}$, and $\mathrm{H}_{2} \mathrm{O}_{2}$.

\subsection{Data Analysis}

The data were processed with Microsoft Excel and Origin 8.5 software. Statistical analysis was carried out by using SPSS 13.0. The data were analyzed by oneway analyses of variance (ANOVA) with Duncan's multiple range test to separate means. Differences were considered significant at $P<0.05$.

\section{Results and Analysis}

\subsection{Effects of Intercropping on Plant Growth and As Uptake}

Figure 1 illustrates the biomass, As concentration, and growth condition of Panax notoginseng and Pteris vittata growing in different As-contaminated soils. For Panax notoginseng in intercropping model, biomass could be respectively increased by $40.7-211.6$ and $2.1-153.3 \%$ in H-As and M-As treatment, while inhibited by $11.0-19.1$ $\%$ in the L-As treatment. In monoculture model, the As concentrations of root and leaf in H-As treatment and root in M-As treatment exceeded the standard of GTSIEMPP by $848.6,62.6$, and $45.2 \%$, respectively. Intercropping could significantly reduce the As concentration in different parts of plant by 30.9-54.3 and 9.1-54.3\%, respectively, in H-As and M-As treatments, while increase by 5.4-76.2 \% in L-As treatment. For Pteris vittata in intercropping model, the biomass in different parts of plant was decreased by 50.0-52.4 and 5.0-47.8 \%, respectively, in $\mathrm{H}$-As and M-As treatments, while increased by $92.7-118.9 \%$ in L-As treatment. Intercropping could respectively promote the As concentration in different parts of plant by $1.2-17.0,15.2-16.7$, and $7.8-141.9 \%$ in H-As, M-As, and L-As treatments. Although the As concentration and biomass of Pteris vittata exhibited clear regularity, the difference was not significant.

3.2 Effects of Intercropping on the As Concentration, $\mathrm{pH}$, and As Fractions in the Rhizosphere Soil of Plants

For As concentration and $\mathrm{pH}$ in the rhizosphere soils of plants, intercropping could reduce them by $0.4-5.6 \%$ and $0.4-0.5$ units, respectively, while the results between monoculture and intercropping did not show significant difference.

The As fractions in the rhizosphere soils of the Panax notoginseng are given in Fig. 2. There were different composition patterns in the soil of different As treatments for monoculture. The H-As treatment presented a pattern of the following: F3 $(40.0 \%)>\mathrm{F} 2(35.2 \%)>\mathrm{F} 4$ $(13.9 \%)>$ F5 $(10.8 \%)>$ F1 $(0.8 \%)$. The M-As treatment presented a pattern of the following: F4 (27.4\%)> F3 (27.1 \%)>F5 (22.8 \%)>F2 (22.4\%)>F1 (0.3\%). The L-As treatment presented a pattern of the following: F2 (31.8 \%)>F5 (30.9\%)>F3 (19.3\%)>F4 (18.0\%)> F1 (not detected). For intercropping, it could not only significantly affect the concentration of F1, but also 

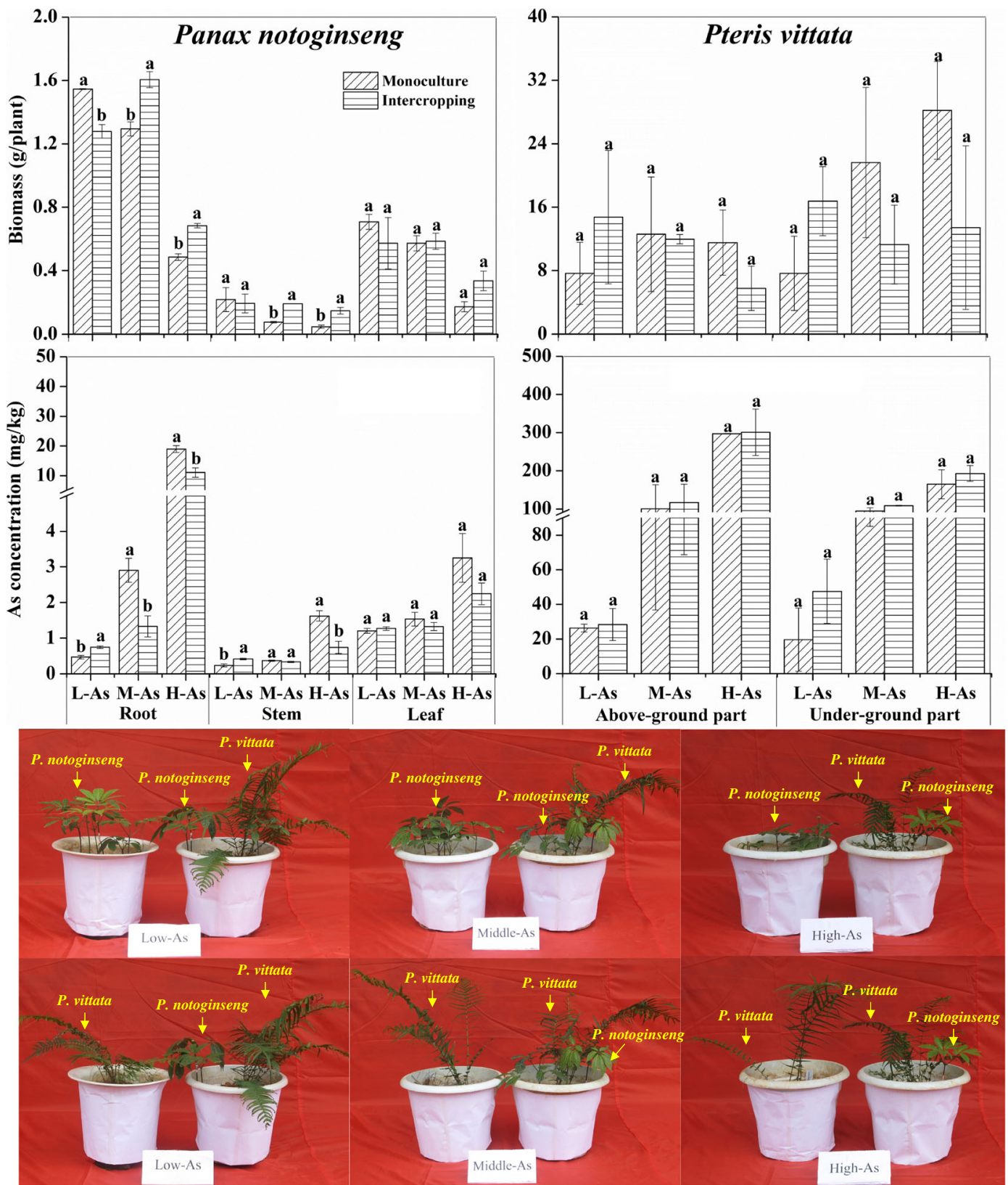

Fig. 1 Biomass, As concentration, and growth condition of Panax notoginseng and Pteris vittata growing in soils with different As concentrations; different small letters between a data pair indicate a statistically significant difference between them $(P<0.05)$

promote the transformation of the strong-bound fraction to the weak adsorbed ones. The ratios of $\mathrm{F} 1$ treated with $\mathrm{H}-\mathrm{As}$ and M-As significantly decreased from 0.8 and 0.3 to 0.6 and $0.2 \%$, and the ratio of F1 treated with LAs increased from not detected (ND) to $0.1 \%$. The L-As demonstrated a significant transformation trend from $\mathrm{F} 5$ to F4, F3, and F2, and the ratios of F4, F3, and F2 increased from $18,19.3,31.8$, to $20.1,33.4$, and 21.3
$\%$. Besides that, there were no significant differences among F2-F5 in H-As and M-As treatments.

\subsection{Effects of Intercropping on As Transfer Factor} and Speciation in Panax notoginseng

Transfer factor (leaf concentration/root concentration, $\mathrm{TF}$ ) represented the transport ability of heavy metal in 


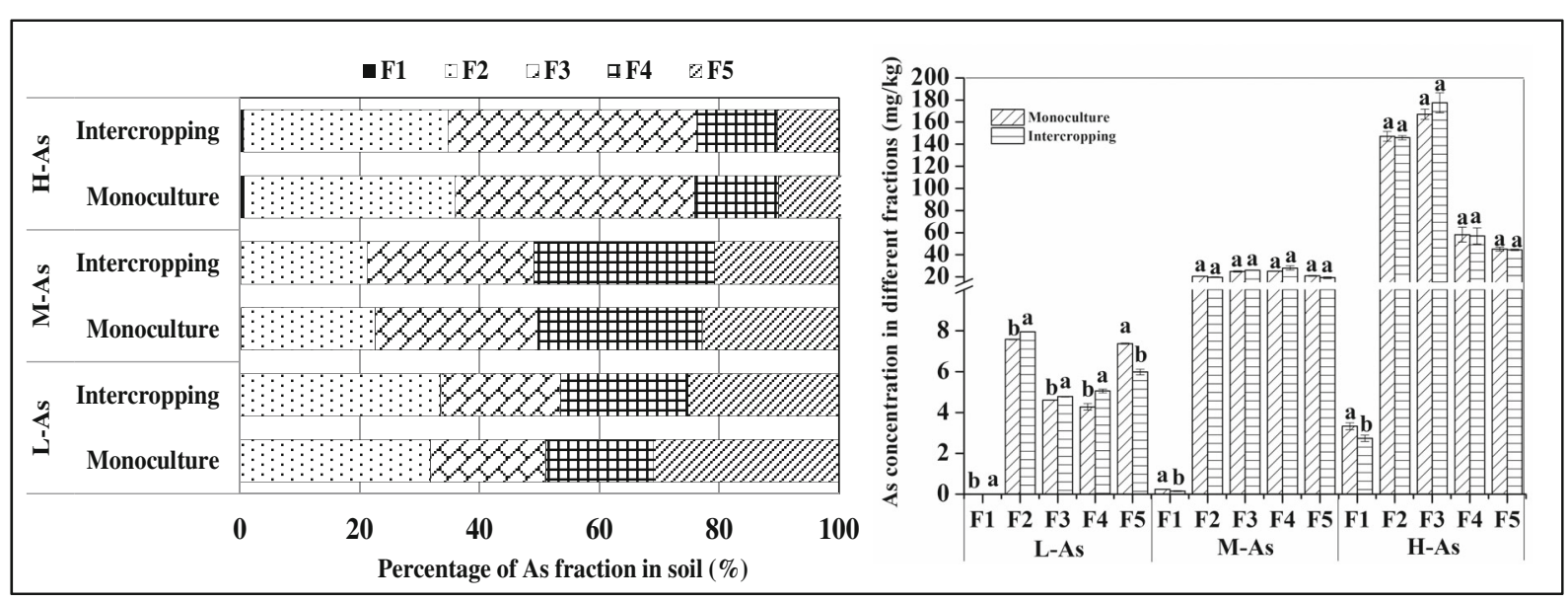

Fig. 2 Effects of intercropping on As fractions in rhizosphere soils of Panax notoginseng. F1 non-specifically adsorbed As, F2 specifically adsorbed As, F3 amorphous and poorly crystalline hydrated $\mathrm{Fe}$ and $\mathrm{Al}$ oxide-bound $\mathrm{As}, F 4$ well-crystallized hydrated $\mathrm{Fe}$ and $\mathrm{Al}$ oxide-bound As, $F 5$ residual As

could not only effectively reduce the concentrations of $\mathrm{As}(\mathrm{III})$ and $\mathrm{As}(\mathrm{V})$ in the root and xylem sap, but also significantly promote the proportions of As(III), which were increased to 97.8 and $72.4 \%$.

\section{Discussion}

The present results from pot trials indicate that intercropping with Pteris vittata is a good option for solving As contamination problem of Panax notoginseng in the moderately As-contaminated soil. For the production, intercropping could significantly increase the biomass of roots in Panax notoginseng by 39.8 and $24.0 \%$, respectively, in H-As and M-As treatments. For the quality, intercropping could significantly reduce the As concentration in roots of Panax notoginseng by 41.5 and $54.3 \%$, respectively, in H-As and M-As treatments. For economic efficiency, intercropping is much cheaper than other control technologies in As-contaminated farmland. Intercropping with Pteris vittata enabled the meeting of Panax notoginseng in the M-As-contaminated areas with the standard of GTSIEMPP (As concentration $<2 \mathrm{mg} / \mathrm{kg}$ ), while some more supporting technologies, such as mowing, stabilization, and so on, are required in the H-As-contaminated areas (Yan et al. 2013).

In the present study, the $\mathrm{pH}$, As concentration and fractions in soil, and the As TF and speciation in Panax notoginseng were also investigated to reveal the effects of the intercropping of Pteris vittata on the As

Different small letters between a data pair indicate a statistically significant difference between them $(P<0.05)$ 
Fig. 3 The proportion of As speciation in different parts of Panax notoginseng treated with H-As

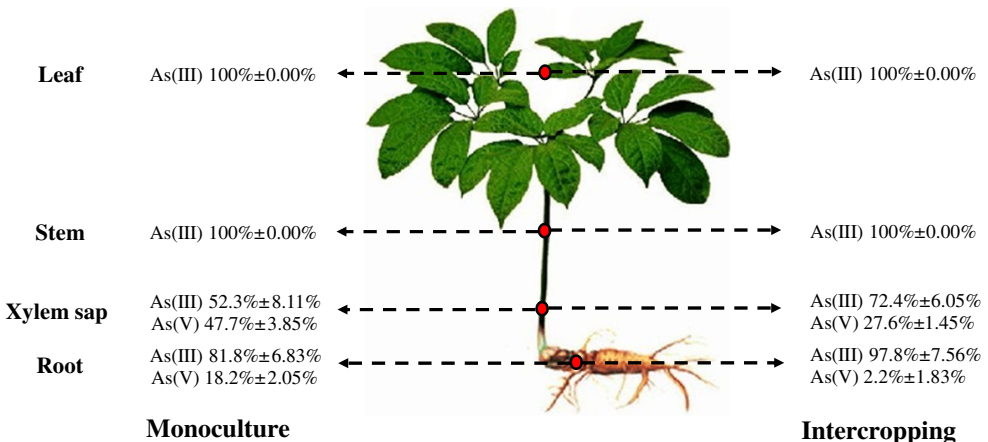

characteristics of occurrence, transfer, and transformation in the system of plant-soil.

For the $\mathrm{pH}$ and As fractions in soil, the results between monoculture and intercropping did not show significant difference. For As fractions in soil, intercropping could decrease the nonspecifically adsorbed As concentration in the rhizosphere to reduce the probability of As uptake by Panax notoginseng. F1 represented the exchangeable or outer-sphere chelate As, and the risk of As uptake by plants is the greatest (Wenzel et al. 2001). In general, Pteris vittata has the unique ability of As accumulation and can adjust the soil $\mathrm{pH}$ to increase the available As content in the rhizosphere (Tu et al. 2004). For example, Gonzaga et al. (2009) found that Pteris vittata could decrease the soil $\mathrm{pH}$ by $0.74-0.92$ units, leading to an increase of 2.6-3.8 times the available As in the rhizosphere soil. In this study, intercropping could decrease the $\mathrm{pH}$ in L-Astreated soil of Panax notoginseng by 0.5 units and increase the F1 concentration by 78 times (from ND to $0.0078 \pm 0.0013 \mathrm{mg} / \mathrm{kg}$ ). However, in H-As and M-As treatments, intercropping decreased the $\mathrm{F} 1$ concentrations by $17.8 \%$ (from $3.33 \pm 0.17$ to $2.74 \pm 0.16 \mathrm{mg} / \mathrm{kg}$ ) and $34.3 \%$ (from $0.24 \pm 0.01$ to $0.16 \pm 0.03 \mathrm{mg} / \mathrm{kg}$ ) in the rhizosphere soil. Fitz et al. (2003) suggested that for the high As-contaminated soils, Pteris vittata would activate and absorb F1; however, the alimentative As from F2-F5 to F1 could not maintain its level, thus resulting in the significantly decreased concentration of F1. F2F5 was the inner-sphere chelate or crystal-bound As, which has the potential risk of migration (Krysiak and Karczewska 2007). In this study, intercropping with Pteris vittata could significantly promote the transformation of soil strong-bound As fractions to weak adsorbed ones in L-As treatment, while the difference of results in M-As and H-As was not significant.
For the As transfer and transformation in Panax notoginseng, intercropping could promote the As transfer to the aboveground part of plant, thereby further reducing the As concentration in root (the main medicinal active part of the herb). Yan et al. (2011) found that Panax notoginseng had a strong As transfer ability, and its average As TF was as high as 3.3. In general, As would be accumulated in the root of terrestrial plant when its concentration in plant was excessive (Ali et al. 2009). In this study, intercropping could significantly reduce the As uptake by Panax notoginseng, thus significantly increasing their TF values from 1.01 to 1.68 in M-As treatments. In addition, it was also revealed that the reduction of $\mathrm{As}(\mathrm{V})$ in the root of Panax notoginseng may be an important cause of limiting the As transfer to the aboveground part. Generally, the root of the terrestrial plant has strong As reduction capacity; thus, As(III) was the main speciation in the plant tissue and xylem sap. For example, As(III) accounted for 92 and $99 \%$ in the tissue of O. sativa and Lycopersicon esculentum and about 81 and $93 \%$ in the xylem sap (Ma et al. 2008; Xu et al. 2007). Due to the fact that As(III) may interact with phytochelatins (PCs) and be accumulated in cytoplasm, the reduction reaction at the roots was often considered to be the key to the detoxification of As in plants (Raab et al. 2005). However, Dhankher et al. (2006) discovered that the As TF was increased by 25 times by inhibiting the activity of $\mathrm{As}(\mathrm{V})$ reductase in Arabidopsis thaliana. It indicated that $\mathrm{As}(\mathrm{V})$ reduction in the roots might be a key step in limiting the As transfer to the aboveground part. In this study, intercropping reduced the ratio of $\mathrm{As}(\mathrm{V})$ to $2.2 \%$ in root of Panax notoginseng treated with $\mathrm{H}-\mathrm{As}$, while the ratio of $\mathrm{As}(\mathrm{V})$ in xylem sap was still as high as $27.6 \%$, indicating that the reduction reaction of $\mathrm{As}(\mathrm{V})$ in the roots indeed limited the process of As transfer to the 
aboveground part. Therefore, how to effectively inhibit the $\mathrm{As}(\mathrm{V})$ reduction in root and thus further reduce the accumulation of As in the root will be the focus of future research.

\section{Conclusion}

Intercropping with Pteris vittata may be one of the options for the reduction of As accumulation in Panax notoginseng in the moderately As-contaminated soil. Intercropping could decrease the nonspecifically adsorbed As concentration in the rhizosphere to reduce the probability of As uptake by Panax notoginseng. Intercropping could also promote the As transport to the aboveground part, thereby further reducing the As concentration in root. The reduction reaction of $\mathrm{As}(\mathrm{V})$ in the roots limited the process of As transport to the above ground.

Acknowledgments This work is supported by the Science Foundation for Excellent Young Talents of the Institute of Geographic Sciences and Natural Resources Research, Chinese Academy of Science (CAS) (No. 2012RC203), the National Natural Science Foundation of China (No. U1361203), the Fundamental Research Funds for the Central Universities of China University of Mining and Technology (Beijing) (No. 2010YH05), the special fund for agro-scientific research in the public interest (grant no. 201403015).

\section{References}

Ali, W., Isayenkov, S. V., Zhao, F. J., \& Maathuis, F. (2009). Arsenite transport in plants. Cellular and Molecular Life Sciences, 66(14), 2329-2339.

Chen, T. B., Wei, C. Y., Huang, Z. C., Huang, Q. F., Lu, Q. G., \& Fan, Z. L. (2002). Arsenic hyperaccumulator Pteris vittata L. and its arsenic accumulation. Chinese Science Bulletin, 47, 902-905.

Dhankher, O. P., Rosen, B. P., McKinney, E. C., \& Meagher, R. B. (2006). Hyperaccumulation of arsenic in the shoots of Arabidopsis silenced for arsenate reductase, ACR2. Proceedings of the National Academy of Sciences of the United States of America, 103(4), 5413-5418.

Djordjevic, M. A., Oakes, M., Li, D. X., Hwang, C. H., Hocart, C. H., \& Gresshoff, P. M. (2007). The Glycine max xylem sap and apoplast proteome. Journal of Proteome Research, 6(9), 3771-3779.

Feng, G. Q., Liu, Y. Z., Zhang, W. B., \& Wu, Z. C. (2005). Research on polluted channel of arsenic in the Panax notoginseng. Journal of Chinese Medicinal Materials, 28(8), 645-647 (in Chinese).
Fitz, W. J., Wenzel, W. W., Zhang, H., Nurmi, J., Stipek, K., Fischerova, Z., Schweiger, P., Köllensperger, G., Ma, L. Q., \& Stingeder, G. (2003). Rhizosphere characteristics of the arsenic hyperaccumulator Pteris vittata L. and monitoring of phytoremoval efficiency. Environmental Science \& Technology, 37(21), 5008-5014.

Gonzaga, M. I. S., Ma, L. Q., Santos, J. A. G., Matias, \& M. I. S. M. (2009). Rhizosphere characteristics of two arsenic hyperaccumulating Pteris ferns. Science of The Total Environment, 407(16), 4711-4716.

Gove, B., Hutchinson, J. J., Young, S. D., Craigon, J., \& McGrath, S. P. (2002). Uptake of metals by plants sharing a rhizosphere with the hyperaccumulator Thlaspi caerulescens. International Journal of Phytoremediation, 4(4), 267-281.

Guo, H. B., Cui, X. M., An, N., \& Cai, G. P. (2010). Sanchi ginseng (Panax notoginseng (Burkill) F. H. Chen) in China: distribution, cultivation and variations. Genetic Resources and Crop Evolution, 57, 453-460.

Krysiak, A., \& Karczewska, A. (2007). Arsenic extractability in soils in the areas of former arsenic mining and smelting, SW Poland. Science of the Total Environment, 379(2-3), 190200.

Li, N. Y., Li, Z. A., Zhuang, P., Zou, B., \& McBride, M. (2009). Cadmium uptake from soil by maize with intercrops. Water, Air, \& Soil Pollution, 199(1-4), 45-46.

Lin, L. Y., Yu, B. B., Liao, X. Y., Yan, X. L., \& Zhang, Y. X. (2013). Contents and health risk of As and heavy metals in Panax notoginseng and their pharmaceutical preparations. Asian Journal of Ecotoxicology, 82(2), 244-249 (in Chinese).

Ma, L. Q., Komar, K. M., Tu, C., Zhang, W. H., Cai, Y., \& Kennelley, E. D. (2001). A fern that hyperaccumulates arsenic - a hardy, versatile, fast-growing plant helps to remove arsenic from contaminated soils. Nature, 409(6820), 579.

Ma, J. F., Yamaji, N., Mitani, N., Xu, X. Y., Su, Y. H., McGrath, S. P., \& Zhao, F. J. (2008). Transporters of arsenite in rice and their role in arsenic accumulation in rice grain. Proceedings of the National Academy of Sciences, 105(29), 9931-9935.

$\mathrm{Ng}$, T. B. (2006). Pharmacological activity of sanchi ginseng (Panax notoginseng). Journal of Pharmacy and Pharmacology, 58(8), 1007-1019.

Raab, A., Schat, H., Meharg, A. A., \& Feldmann, J. (2005). Uptake, translocation and transformation of arsenate and arsenite in sunflower (Helianthus annuus): formation of arsenic-phytochelatin complexes during exposure to high arsenic concentrations. New Phytologist, 168(3), 551-558.

SSICA (Soil Sci. Ch. Acad.). (1980). Physical and chemical analyses of soils. Shanghai Academic Press, China. (in Chinese).

Tang, Y. T., Deng, T. H. B., Wu, Q. H., Wang, S. Z., Qiu, R. L., Wei, Z. B., Guo, X. F., Wu, Q. T., Lei, M., Chen, T. B., Echevarria, G., Sterckeman, T., Simonnot, M. O., \& Morel, J. L. (2012). Designing cropping systems for metal-contaminated sites: a review. Pedosphere, 22(4), 470-488.

Tu, S. X., Ma, L., \& Luongo, T. (2004). Root exudates and arsenic accumulation in arsenic hyperaccumulating Pteris vittata and non-hyperaccumulating Nephrolepis exaltata. Plant and Soil, 258, 9-19.

Wenzel, W. W., Kirchbaumer, N., Prohaska, T., Stingeder, G., Lombi, E., \& Adriano, D. C. (2001). Arsenic fractionation in soils using an improved sequential extraction procedure. Analytica Chimica Acta, 436(2), 309-323. 
Xie, J. Q., Lei, M., Chen, T. B., Li, X. Y., Gu, M. H., \& Liu, X. H. (2010). Phytoremediation of soil co-contaminated with arsenic, lead, zinc and copper using Pteris vittata L.: a field study. Acta Scientiae Circumstantiae, 30(1), 165-171 (in Chinese).

Xu, X. Y., Mcgrath, S. P., \& Zhao, F. J. (2007). Rapid reduction of arsenate in the medium mediated by plant roots. New Phytologist, 176(3), 590-599.

Yan, X. L., Liao, X. Y., Yu, B. B., \& Zhang, W. B. (2011). Accumulation of soil arsenic by Panax notoginseng and its associated health risk. Environmental Science, 32(3), 880885 (in Chinese).

Yan, X. L., Lin, L. Y., Liao, X. Y., \& Zhang, W. B. (2012). Arsenic accumulation and resistance mechanism in Panax notoginseng, a traditional rare medicinal herb. Chemosphere, 87(1), 31-36.

Yan, X. L., Lin, L. Y., Liao, X. Y., Zhang, W. B., \& Wen, Y. (2013). Arsenic stabilization by zero-valent iron, bauxite residue, and zeolite at a contaminated site planting Panax notoginseng. Chemosphere, 93(4), 661-667. 